\title{
Tinkering with tasks knows no bounds: ESL Teachers' Adaptations of Task-Based Language-Teaching
}

John L. Plews and Kangxian Zhao

Research on implementing task-based language-teaching (TBLT) shows that adapting TBLT in ways that are inconsistent with its principles is common among nonnative-speaker English-as-a-foreign-language teachers. Our study of Canadian native-speaker English-as-a-second language teachers reveals how they also adapt TBLT in ways that are incongruent with its theoretical underpinnings, turning it into Presentation-Practice-Production. We thus question speaker identity as an indicator of a teacher's propensity to adapt TBLT and call for professional development on the effective practice of TBLT for all English-language teachers regardless of their speaker identities.

La recherche démontre qu'il est commun pour les enseignants d'ALS dont l'anglais n'est pas la langue maternelle d'adapter l'approche de l'enseignement des langues centré sur les tâches (task-based language-teaching-TBLT) selon des façons qui sont incompatibles avec ses principes. Notre étude d'enseignants d'ALS dont l'anglais est la langue maternelle révèle qu'eux aussi adaptent l'approche TBLT selon des méthodes contraires à ses fondements théoriques, la transformant en "présentation, pratique, production». Nous remettons ainsi en question l'identité du locuteur comme indicateur de la propension d'un enseignement à adapter l'approche TBLT et demandons une formation professionnelle portant sur l'application efficace de la méthode et visant tous les enseignants d'anglais peu importe leur langue maternelle.

\section{Introduction}

In this article, we discuss the implementation of task-based language teaching (TBLT) by English-as-a-second- or foreign-language (ESL/EFL) teachers. Candlin (2001) pointed out the lack of research on TBLT in both the "educational curriculum in macro" and "the curriculum in micro," that is, "the place and role of tasks in the systematic and sequenced organizations of classroom practice" (p. 230). Similarly, Van den Branden (2006) and Samuda and Bygate (2008) remarked on how little research had been conducted on how specifically teachers perceive their role in TBLT or construe tasks in lessons. Nonetheless, several studies (Carless, 2003, 2004, 2007, 2009; Gatbonton \& Gu, 1994; Jeon \& Hahn, 2006; Xu, Liu, \& Jiang, 2008; Littlewood, 2004, 2007; Lopes, 2004; McDonough \& Chaikitmongkol, 2007; Watson Todd, 2006) have 
been conducted in EFL contexts in Brazil, China, Hong Kong, Korea, and Thailand. These studies have focused almost exclusively on nonnativespeaker (NNS) teachers, revealing their successes and challenges as well as the constraints placed on TBLT. We believe that the one-sided participant focus of these studies suggests a potentially diversionary dichotomy between studied NNS teachers and unstudied native-speaker (NS) teachers, which may be counterproductive to overall improvement in the EFL/ESL profession. Thus we carried out a qualitative study of NS ESL teachers in Atlantic Canada that inquired into their knowledge, perceptions, and experience of second-language teaching methods in general in order to examine their understandings and practice of TBLT in particular. In the following, we briefly review the structure and basic principles of TBLT and synthesize recent research on its implementation. Then we describe our study and present how NS ESL teachers construe TBLT. By comparing our findings with those of existing research, we reject the impression given by that research that effective implementation of TBLT is related to speaker identity categories.

\section{A Brief Overview of TBLT}

TBLT is an instructional approach that has developed in communicative language teaching (CLT) by recognizing the usefulness of tasks (Prabhu, 1987). In TBLT, teachers set language-learners genuinely purposeful, problem-oriented, or outcome-driven tasks, which are thus comparable to realworld activities, for the sake of encouraging meaningful communication and providing a context in which to study language (Willis, 1996). Following Willis's framework, tasks are anticipated with task-enabling pre-task language activities (such as brainstorming, classifying, comparing, glossing a short text or video, ranking, sequencing, etc.) and clear instructions. The tasks are followed by planning and presenting a report on the task outcome as well as post-task focus-on-form activities based on discrete grammar items that emerged as new or difficult for learners during task and report completion. The communication is meaningful because learners have a stake in completing the task rather than practicing language for its own sake. Especially during the post-task activities, learners are encouraged to notice and analyze the gaps in their linguistic output as compared with more proficient or authentic examples. Skehan (2003) has identified strong and weak or focused variations of TBLT. A strong task cycle does not pre-select any particular language structure in order to attain task completion. In contrast, a weak task cycle is predisposed to teaching specific language structures required for task completion (whether learners use them or not). Learners are still encouraged on task completion to focus on forms, although now the teacher chooses the forms at the outset. Both variations allow for flexibility in how teachers apply tasks to suit students' needs and level, 
curriculum goals, prior teaching experience, and local circumstances (Ellis, 2003; Samuda \& Bygate, 2008).

Above all, TBLT is not the so-called traditional language teaching that introduces grammar structures according to the sequenced contents of textbooks (Ellis, 2002; Swan, 2005): it is not Presentation-Practice-Production (PPP), which requires teachers to introduce vocabulary items or grammar rules and expects students to manipulate decontextualized sentences before they write or perform something, to be assessed for accuracy rather than meaningful content, successful communication, or relevance to student selfactualization. Nor is TBLT the elimination of presentation and practice in order to emphasize production without forethought or reflection (compare Swan). Rather, TBLT is informed by principles derived from theories of and research into second-language learning and teaching (Ellis, 2003; Samuda \& Bygate, 2008; Swan). The following is a synopsis of the most significant principles (Bygate, Skehan, \& Swain, 2001; Candlin, 2001; Ellis; Long, 1991; Nunan, 1991, 1993; Richards \& Rogers, 2001; Samuda \& Bygate; Skehan, 1998, 2003; Willis, 1996).

- Learners require exposure to the real (authentic) and varied language of speakers of the target language (often modified; always comprehensible).

- Learners must be exposed to and use the kind of language that they want and need for their own interests or purposes.

- Learners must be provided with opportunities for unrehearsed and meaningful language use in purposeful interaction, where they take informed risks, make choices, and negotiate meaning while seeking solutions to genuine queries.

- Teachers ensure that activities are interconnected and organized with clearly specified objectives and promote the desire to learn.

- Teachers should elicit self-correction, enable personalized feedback, and consider learners' individual developing language systems (interlanguage).

- Teachers must set learners activities that help them notice language forms; induction/discovery is preferable to deduction/presentation; teachers should (explicitly) instruct form in the context of activities where meaning is primary.

- The whole language (listening, speaking, reading, and writing) should be integrated.

- Teachers evaluate learners in a formative manner and in terms of the process of achieving a goal; learners need to evaluate their own performance and progress.

Given such principles, TBLT is regarded as more effective than traditional teaching methods (Bruton, 2005; Swan). 


\section{Implementation of TBLT}

Studies of EFL teachers' perceptions of TBLT and its implementation have importantly shown that these teachers experienced a range of genuine difficulties and uncertainties. The first issue was teachers' attitudes toward methodology and classroom management. Some EFL teachers were reluctant to use communicative approaches (Gatbonton \& Gu, 1994), favoring PPP (Carless, 2009). They were concerned about discipline and the role of the teacher, prioritized textbook coverage (Carless, 2003), and preferred quiet, managed classrooms to noisy activities (Carless, 2004).

Second, teachers had misgivings about student performance. They were concerned about students' language proficiency (Carless, 2003; Watson Todd, 2006), their use of the mother tongue, the less than expected amounts of target language production (Carless, 2004), lack of accuracy, and copying habits (Watson Todd). Some thought TBLT delayed strong students (Jeon \& Hahn, 2006). However, other teachers welcomed the effectiveness of TBLT for small-group work, interaction, motivation (Jeon \& Hahn), independence, skills and strategies development, and relevance to student needs (McDonough \& Chaikitmongkol, 2007).

Third, teachers indicated a lack of theoretical knowledge of tasks or TBLT (Carless, 2003; Xu et al., 2008; Littlewood, 2004). This was reiterated in teachers' opinions that TBLT predominantly entailed oral production (Carless, 2007) and that the roles of grammar and checking for accuracy were unclear or lacking (Jeon \& Hahn, 2006; Xu et al.; Littlewood; Lopes, 2004; McDonough \& Chaikitmongkol, 2007).

Practical issues were the largest group of concerns and challenges. Teachers may have personally lacked proficiency in English (Jeon \& Hahn, 2006) or felt insecure (Watson Todd, 2006). They may have had classes with large enrollments (Jeon \& Hahn). They found that their preparation time increased, adding to their workload, or they lacked sufficient preparation time (Carless, 2003; Jeon \& Hahn; Watson Todd). Similarly, they were challenged by the limited class time available for completing tasks and all the other activities in the TBLT cycle such as task repetition or focusing on form (Carless; Lopes, 2004; McDonough \& Chaikitmongkol, 2007). Teachers did not have the systematic knowledge for implementing tasks or for adjusting from a teacher-centered approach to the learner-centeredness of TBLT (Jeon \& Hahn; Xu et al.; McDonough \& Chaikitmongkol). Further systematic challenges included students' unfamiliarity with this learning process (Jeon \& Hahn), the complexity of tasks (Carless, 2009), making connections between tasks (Watson Todd) and transitions between various materials, and responding spontaneously to students with clear instructions and accurate feedback (McDonough \& Chaikitmongkol).

Assessment raised some final practical concerns for teachers. Some did not know how to assess learners' performance (Jeon \& Hahn, 2006), whereas 
others were bothered by a tendency to mark subjectively (Watson Todd, 2006). Elsewhere, there was a mismatch between tasks and traditional formoriented examinations (Carless, 2007).

As a consequence of their difficulties and concerns, EFL teachers often avoided TBLT in favor of traditional explicit grammar instruction and vocabulary and examination drills (Carless, 2003; Jeon \& Hahn, 2006; Xu et al., 2008; Littlewood, 2007). Sometimes, teachers combined the communicative method with traditional form- and rule-focused teaching (Gatbonton \& Gu, 1994). Otherwise, they practiced some adaptation of TBLT that did not adhere to its principles and resembled communicative practice exercises (Carless, 2004), including the deductive presentation of grammar (Carless, 2007) as a language focus at the beginning of the lesson and either omitting the post-task analytical stage or replacing it with correction (Carless, 2009). In one institution, English grammar classes were added in the mother tongue (Lopes, 2004). In another, where teachers were to teach a whole curriculum using TBLT, they shifted from strong to weak TBLT by reducing the number of tasks, placing more emphasis on explicit teaching of grammar, discourse functions, and writing and increasing the amount that exams contributed to the final grade (Watson Todd, 2006). Similarly, in response to teachers' challenges, Carless proposed a situated weak version of TBLT that incorporated direct grammar instruction in the pre-task stage and PPP-style teaching, despite their theoretical incompatibility with TBLT. He also suggested further explanation of the post-task stage, links between tasks and examinations, and using more reading and writing tasks.

Besides the above-mentioned difficulties, a further issue emerges on reviewing studies of EFL teachers implementing TBLT: the focus is almost exclusively on teachers with NNS identities. Only McDonough and Chaikitmongkol $(2007)$ and Carless $(2007,2009)$ identified collectively four NS teachers and four NS teacher educators (Carless, personal communication, September 3, 2009) in an overall large majority of NNS study participants. Databases, books, and the Internet reveal no comparable studies of NS EFL or ESL teachers. NS ESL teachers seem not to have warranted any scholarly attention on their perceptions of TBLT. Such one-sidedness in the participant focus and outcomes of studies on implementing TBLT in EFL contexts could give the impression that resisting, adapting, or even failing to comprehend TBLT is the dubious distinction of EFL teachers with NNS identities.

The revelation that one set of teachers-NNS-has problems with a particular approach does not necessarily mean that others-NS-do not. Yet such an assumption is well represented in the language-teaching profession. We are bound to recall the received wisdom in the ESL profession that CLT is a NS-centered method appropriate for immersion contexts in core Englishspeaking countries and therefore foreign especially in non-Western parts of the world (Holliday, 1994). Being seen to promote the value of, and the 
values of, the NS, CLT was considered an instrument of English linguistic imperialism (Phillipson, 1992).

Such important critical, geocultural concerns preceded a number of studies on implementing CLT (Gorsuch, 2000; Karavas-Doukas, 1996; Li, 1998; Sun \& Cheng, 2002; Yu, 2001) that indicated the difficulties of particularly NNS EFL teachers. Teachers' facility with CLT became associated more with nontraditional educational culture and NS identity than with the extent of pedagogical knowledge development. A case in point is Sun and Cheng's report on CLT in EFL classes at a private college in China; here difficulties caused by the NNS teachers' traditional "test-, teacher-, and textbook-centered" (p. 73) perceptions of teaching and limited proficiency in spoken English led the researchers to recommend "a balanced methodology" (p. 78) across the curriculum that relied on methodologically segregating teachers according to the apparent qualities of respective speaker identities: Chinese NNS teachers taught traditional text-based grammar classes, whereas expatriate NS teachers taught communication. Sun and Cheng reasoned, "It is relatively easier for an expatriate teacher to use communicative methodology" and "Grammar and vocabulary teaching [by NNS speakers] can be relatively more important than communication in EFL contexts" (p. 78), and thus "both local and expatriate teachers can do what they are good at" (2002, p. 82). To Sun and Cheng, NS and NNS EFL teachers had mutually exclusive talents when it came to teaching methods: NNS EFL teachers had difficulty with communicative approaches, whereas their NS counterparts, in the absence of evidence, found them easy.

Research on implementing TBLT in EFL contexts echoes Sun and Cheng's (2002) remarks about CLT and teachers' speaker identities. Indeed, the same researchers also reported early observations of a further initiative to introduce a task-based syllabus that showed some NNS teachers continuing with traditional teaching, turning communicative activities into grammar exercises. Yet methodological mutual exclusivity based on speaker identities raises operational and critical issues. Sun and Cheng pointed out the ineffectiveness, inconsistency, confusion, conflict, and absence of professional exchange that their so-called balanced curriculum caused. Certainly the implementation of methodological innovations can deprive local teachers of a sense of ownership of the curriculum and will fail unless it is guided by their experiences of the given context (Van den Branden, 2006; Watson Todd, 2006). But if TBLT is a superior approach and yet also beyond the comfort of NNS EFL teachers, then by handing its ownership to NS teachers, the ESL profession risks putting down a new layer of instructional imperialism.

As NNS teachers of foreign and second languages who use TBLT, we find the research on NNS EFL teachers at odds with our professional experiences. Although we experienced the increased preparation time, inevitable creation of appropriate materials, and trial-and-error growing pains that teachers 
encounter when shifting to a new approach, we have not found TBLT more difficult than any other approach. On the contrary, TBLT has been more interesting for us and more relevant, motivating, and effective for our students. But we are also aware that we have benefited from excellent role models, have read widely about the approach before using it, and have enjoyed the freedom to introduce it at our own pace and on our own terms. We are also fortunate to have received high levels of education, lived in the culture of the target language, and taught in both foreign-language and immersion settings. We do not at all mean to dismiss the concerns that NNS EFL teachers expressed in the studies mentioned above. Their issues-especially concerning language proficiency, self-efficacy, and pedagogical content knowledge - are significant and must be addressed with opportunities for level-appropriate language-learning and professional development in teaching methodology. However, we believe that given sufficient and appropriate support and materials, NNS are well suited for TBLT, as their personal second-language (L2) learning histories and dynamic language egos may be useful resources for anticipating learners' difficulties and determining particular tasks that may facilitate gaps and noticing (Medgyes, 1992). We also believe that NNS EFL teachers' issues with TBLT are not exclusively their domain.

Studies of NS modern-language teachers' experiences of TBLT (Leaver \& Kaplan, 2004; Maly, 1993; Saito-Abbott, 2004; Van Avermaet, Colpin, Van Gorp, Bogaert, \& Van den Branden, 2006; Van den Branden, 2006) have raised similar issues to those of NNS EFL teachers (although none of the studies indicates the participants' speaker identities, it is most likely that in each case, most if not all the teachers were NS given the specific combinations of target languages and locations of instruction). The use of TBLT was impeded by the teachers' previous methodological experiences (Saito-Abbott; Van Avermaet et al.; Van den Branden) and students' expectation of traditional assessment (Leaver \& Kaplan; Maly). Teachers had problems with relinquishing control and avoided noisy group work (Van den Branden). They had difficulty finding time for professional development, creating materials, class preparation, and task completion (Leaver \& Kaplan; Maly; Saito-Abbott). They stressed linguistic accuracy, introduced tasks after explicit grammar teaching, explained words before students could negotiate meaning, provided schemes for writing tasks, and gave answers during reading tasks (Van Avermaet et al.; Van den Branden). Despite a positive attitude and adding more functional skills and input in their teaching, these NS teachers either only experimented with TBLT, adopted aspects that most reflected their preexisting practice, or adapted the new approach to the old (Van den Branden).

Thus both NNS EFL teachers and NS modern-language teachers seem to avoid TBLT or to adapt the task framework in ways that are incompatible 
with its principled foundations. There is no evidence that one group is so good at TBLT that it is better than the other (Mitchell \& Lee, 2003). Skehan (2003) referred to teachers in general when remarking that they worried about organizing pre-task activities, teaching sequences, and project work, and otherwise avoided TBLT because it required them to take on a less controlling role. Given the existing focus on NNS EFL teachers, we are interested in discovering specifically NS ESL teachers' perceptions and knowledge of TBLT and in elaborating on how they handle it in their classrooms.

\section{The Study}

We present part of a qualitative study of seven ESL teachers and teacher educators. The study used the interpretive research design of narrative inquiry, which has become an important and insightful means of documenting and understanding teachers' educational experiences, knowledge, and ways of knowing (Carter, 1993; Conle, 2000; Johnson, 2006; Pavlenko \& Lantolf, 2000). Our study investigated what inservice ESL teachers know about language-teaching methodology.

All seven participants in the study were working as ESL instructors at four schools in Atlantic Canada. Two were also experienced ESL teacher educators. Five were born in Canada, and two were born elsewhere. All were fluent speakers of English. One participant was an NNS of English as a child, although she used English as her first language (L1) as an adult. All the English-language NS participants spoke at least one language other than English. Six had studied at various institutions in Canada, and one had studied only in Europe. Their work experience as ESL teachers ranged between 10 and 20 years. Collectively, they had taught English in a large variety of countries in Asia, Africa, Europe, and Oceania, in addition to Canada.

We interviewed all seven participants for approximately 60 minutes, and subsequently conducted classroom observations for up to three hours and follow-up interviews for 20 minutes with five of the seven. The interviews were semistructured in nature. We initiated a conversation that included such topics as how the teachers entered the profession: what their work experience had been; which methods they used; what their education, training, and professional development had been like; what they had learned during these times; and so forth. The interviews aimed to discover the teachers' and teacher educators' understandings of, attitudes toward, and actions concerning language-teaching methods and approaches. The observations provided "isolated snapshots of classroom implementation" (Carless, 2007, p. 599). During these visits, we took descriptive and interpretive notes focusing on the teachers' actions relating to methodology. The descriptive notes recorded the details of the classroom setting, activities, and events. 
The interpretive notes recorded our impressions, reactions, thoughts, and feelings. We transcribed the interviews, cross-checked the transcriptions with notes from classroom observations, and reread the transcriptions and notes together. We surveyed all the written documentation in order to establish the crux of how the participating teachers gave meaning to their experiences and actions concerning methods. We then analyzed the data for particularities, connections, and contradictions with which to configure thematic episodes and compose the narrative. This took shape over several rounds of individual and joint writing.

To present and interpret the data collected, we use a form of narrative inquiry known as narrative analysis (Polkinghorne, 1995). The narrative analysis uses events, actions, time, place, and scene (Clandinin \& Connelly, 2000; Connelly \& Clandinin, 1990) as data to plot a story in order to explain certain outcomes and their complexity as situated, motivated, contingent, and changing. Researchers as interpreters or storytellers create new meaning by selecting, synthesizing, and describing episodes in research participants' lives that they have discovered in the research encounter and see as significant in forming a particular outcome. We have been careful not to write our story as NNS teachers, but rather respect the experiences of our ESL teacher-participants by using mostly their own words. Nonetheless, as authors of the narrative analysis, we acknowledge the important influence of our subjectivity, our prior understandings of the research topic, the dialogic encounter between interpreter and participant, and our necessary awareness of how our understandings have changed in the research process (Smith, 1991).

In the following, we present the narrative of our NS ESL teacherparticipants' shared and particular beliefs and experiences regarding TBLT. We called the narrative "Tinkering with tasks knows no bounds," because this is the crux of their stories. We combine our participants as two composite characters representing the range of their biographical backgrounds and educational histories.

\section{Tinkering With Tasks Knows No Bounds}

Characters. Jane, Canadian-born Chinese, bilingual English and Mandarin NS, ESL teacher with a master's in TESL; taught English for eight years in Korea and various parts of Canada. Jim, New Zealand-born Canadian permanent resident, English NS, learned Italian at university, ESL teacher with a master's in TESL; taught English in New Zealand, Italy, Dubai, and Canada.

Time and place. March 2007, staffroom at their current workplace in a mid-sized city in Atlantic Canada.

Scene. Jane and Jim meet because their director has asked Jim to give a workshop for his colleagues about effective teaching methods. Jim wants to 
check and expand his knowledge with Jane. We join them in mid conversation as they discuss the various methods they have used in their careers and how they handle TBLT.

Jim: You know ... it depends on where I am at the time. I taught using ARC [Authentic, Restricted, and Clarification] in Milan. I taught task-based learning in Auckland. I also taught the communicative approach for a few years. Jane: What method do you use now?

Jim: I teach using a bit of everything. The teachers here do a lot of task-based because we use the textbook American Cutting Edge. They also do guided discovery because we use American Headway. We do a test-teach-test approach. Some use the lexical approach. We do PPP ... usually with the lower levels, or if you are doing an exam class. The students need accurate information for the answers. ... So it really depends on the language centre.

Jane: Yeah, we use task-based and guided discovery where I work now, but those aren't the only methods I've used. Schools always have their approach, don't they?

Jim: That's right. Actually, four years ago, when I was at an international school in Rome, we couldn't agree on what approach we should use as an organization, because we borrowed from audiolingual, grammar translation, and we borrowed from task-based and the communicative approach, and even the silent way, all of these things. So the name we used back then was the principles of eclecticism.

Jane: I think we're all eclectic. It depends a bit on what you're teaching. Jim: That's right. If you have some vocabulary, then teach-test-teach might work nicely. If it's reading and listening, OK, let's use this procedure, which is a receptive skill procedure. If you have speaking or writing activities, then a task might work well. If you have some language or grammar to introduce, what procedures can we use here? Let's use task-based! That can work very well. Guided discovery can work well too. Or the traditional presentationpractice-produce can also be effective.

Jane: Does it matter to you very much which method you use?

Jim: Not really. For me, there are many ways to teach English. I'm using task-based learning with quantifiers. Doesn't mean TBL will work really well for reported speech. I use different methods for everything. I think method has to go with the language points or the skills you are teaching.

Jane: I like task-based language teaching. I learned to do it in my preservice training course right here in the Atlantic. That was over 10 years ago. What do you think about task-based and guided discovery?

Jim: Well, they're both components of communicative learning. For me, communicative learning means introducing the authentic language that learners need. Of course, I think there's an element of communication that has to be accurate, not accurate as in perfect, but accurate as in understandable, comprehensive. 
Jane: Authentic language is really important. In my preservice, we were taught specific ways to deal with children, information about how children learn, which explains how they react to the activities I was asking them to do. I learned how to include a little bit of grammar work, but not too much grammar. I realized then that authentic material has its place with secondlanguage-learner kids.

Jim: What did you do to keep it authentic?

Jane: Well, it's about making connections. Kids tend to learn colors, animals, and numbers really fast in their second language. So I thought, why would I spend four weeks doing that and not connecting it with other things? I wanted to build up things from colors, animals, to descriptions of animals. I wanted the kids to discover things and to work things out. When I was working in Korea, I thought, what do kids really need to do with English? You don't need it to do anything. So teaching kids, you have to look at the functions in their first language. What they do with their first language is what they want to do with their second language. So you have to take things that they would do already, in their L1, and give them the L2 language.

Jim: OK. Is that how you do task-based?

Jane: I start my teaching with an activity, then the students discover the grammar, and then I do a follow-up activity where students apply what they discovered. I guess this also makes me a bit of a guided discovery person. I think it's great. I do it more on a higher level, or with adult learners of different levels.

Jim: Do you think it works for everyone?

Jane: It works for a lot of people, and it also creates energy in the class and discussion between students, which is extremely beneficial. But, you know, if I were ever to learn a language, I probably wouldn't enjoy guided discovery. I would be: Please just tell me. Because that's my learning style. You know: Just show me, tell me, and I'm good. Why am I wasting my time trying to figure it out?

Jim: Not everybody likes the guided discovery bit of task-based. It's not without its issues. Some of my students have a hard time.

Jane: Mine too. In the end, you have to clearly give them the structure. If we are talking about, for example, grammar, you have to be very clear, in the end. As they're going through it, they have to trust that they are going to come to a conclusion, and they are going to know what they want to know by the end. So that tends to keep the ones who don't like guided discovery happy, patient, talking, discussing. And the ones who love it, they are happy working together. They all know that they are going to get a clear answer in the end.

Jim: But the discovery bit isn't all there is to task-based.

Jane: Task-based, of course, is where you don't give them any language; you give them a task, and the language comes out of that. You need to hear 
somebody use the language or they ask you for it. I believe in task-based, but my students have difficulty carrying out the task without enough vocabulary or guidelines.

Jim: Right. Mine too. I know they're supposed to use what they already know to do the task ... and then get more language while they're doing it, or afterward.

Jane: Well it's great to focus on the language afterwards, but my feeling is ... You know, I've done a little bit of research on task-based, and my experience has been that students do want to know at the beginning how they are supposed to say something.

Jim: Yeah, that's a problem.

Jane: And there is a higher level of frustration with students who don't have any language suggestion on how to accomplish a task or who don't have guidelines ...

Jim: Oh, I always give really clear instructions on what they should be doing. When I was learning Italian, some of my teachers could not explain the language clearly. Clear instructions help the students to understand what they are supposed to do, and how to do the task.

Jane: That's the thing about tasks. There's the task, and the language of the instructions, and there's the follow-up language task. I often start with the follow-up language task, because it provides the students with the language that they need to accomplish a more fluency-based task. The students seem to find that more comfortable.

Jim: Yes, I introduce the language points before the students start the task, so the students know the language first. Or I introduce the language in a very controlled task, make sure for accuracy, and then I do a fluency task.

Jane: Yeah, I give my students a list of phrases before they try to do the task. Jim: The students have to have a secure learning environment; they need to have the words.

Jane: And they need to know the structures. The students feel secure if they can use the phrases that they are given, or at least sentence heads.

Jim: I guess there's one way of doing task-based and then there's another.

Jane: Yes, I had students where I did strictly tasks, I mean, purest task-based. And they were just frustrated. They said: Well, how am I supposed to say that? So then you can stop the activity, and you can explain. But in many ways, the interest of the activity is kind of gone, in my experience.

Jim: Well, usually I won't interrupt the students in the middle of a fluency task, when they are communicating with each other. I usually take notes of common errors and wait till the end to go through them then, before we repeat the task.

Jane: There's another thing. I don't find it very necessary to do the task repetition cycle. Once the task is finished, and then you do the language work, what do you do next? OK, have they finished the task or what? 
They've already done it. They've communicated. The communication might not have been pretty, it might not have been accurate, but it was accomplished. But why would they want to go and do it all over again?

Jim: I guess, by the end, the students will have a perfect text, and it's accurate ... You know, I think that in the training workshops, I'll teach guided discovery, task-based learning, teach-test-teach. I don't really think I should do PPP, because everybody does that automatically. You've been a learner for 20 years of your life, and you've seen the teacher present, practice, and produce, and now you're a teacher. So I don't need to introduce that. I might, when I talk about frameworks. This is a very common framework.

Jim and Jane soon wrap up their conversation, but not before Jane tells Jim that he can borrow her old course books from her preservice course on second-language teaching methods.

\section{Discussion}

Research on teachers' perceptions, understandings, and experiences of TBLT has focused predominantly on NNS EFL teachers, with fewer studies on NS teachers of other languages. Positive attitudes are usually associated with appreciation for small-group work; increased learner interaction, motivation, and independence; integrating the development of language skills and learning strategies; and the relevance of learning to students' needs. The more common negative attitudes concern a wide range of issues, including classroom management; students' modest target language proficiency and use; lack of conceptual and practical knowledge; low language proficiency of teachers; lack of professional development and preparation time; and uncertainty about learner-centeredness, the role of grammar, task completion, giving instructions, and providing feedback and assessment. Teachers have thus avoided TBLT for grammar instruction or adapted it into an approach that was incongruent with the principles of TBLT. Teachers' adaptations resembled traditional teaching and included more explicit grammar presentation and drills, ordered rather than flexible tasks, interventions with vocabulary explanations and corrections for accuracy, and no task repetition.

Our inquiry has looked at the perceptions, understandings, and experiences of NS ESL teachers. The participants in our investigation are dedicated, learner-oriented teachers who believe in and freely use TBLT (indicating a sense of ownership), but they do not use it exclusively. They articulate some of the concepts and processes of TBLT, but not others, and they clearly adapt the approach. Its selection can depend on the location or nature of the institution for which the teachers work, a given teacher's pedagogical attitude toward the linguistic focus of a lesson, and their students' defining educational objective (e.g., to pass an examination). Our participants have a broad range of general methodological knowledge and skills, reflecting their teacher education, various teaching experiences, and own language-learn- 
ing. In fact, these three points are also strong factors in determining whether and how a teacher uses TBLT.

The reasons that these NS ESL teachers give for using TBLT reflect their awareness of certain underlying principles from acquisition and learning theories. They understand TBLT to be a communicative approach that introduces authentic language, aims for appropriate NS-like production, and reflects learners' authentic linguistic needs. That is, teachers make available real language input or materials, produced by and for NS, that focus on functional skills that learners need to have in order to use the target language appropriately. They make sure that language content is relevant to learners, require them to use purposeful language, and encourage them to realize real-world functions. These teachers emphasize comprehensive language use and not accuracy. They understand the role that they play in motivating students, the importance of clear instructions, and how to sequence task activities with form focus. They also correctly assume that students learn from noticing their peers' speech or by asking the teacher to fill a gap in their knowledge. There is no doubt that they have success with TBLT.

However, these NS ESL teachers' thinking is not always consistent with TBLT principles. This causes them to use both strong TBLT-which considers the real-world relevance of the task, its completion, and the presentation of its real outcomes-and weak TBLT, according to which they structure their classes in anticipation of a specific skill or discrete language item. They control tasks in ordered steps, and they separate speaking, writing, and grammar as appropriate lesson foci. Although this still facilitates learning, TBLT is rather a flexible, whole-language approach that requires and promotes the integration of language skills. The shift to weaker TBLT occurs out of concern for students' language abilities and the perceived complexity of tasks, not wanting students to search for the words or grammar. Thus when the teachers perceive difficulty, they respond analytically for a number of possible reasons: they do not fully grasp the principles and framework supporting the nonanalytical approach; they lack process-oriented, interactional moves; or they revert to their own language-learning experiences or initial training where the emphasis was on accuracy.

NS ESL teachers are most inconsistent with TBLT when adapting it. They change fundamental parts of the framework. Pre-task language activities may be forgotten, may resemble what ought to be post-task activities, or may be replaced by artificial scaffolding and grammar presentations. For example, although knowing that TBLT requires authentic language input in theory, these teachers may contradictorily believe that in practice it gives no language input except for task instructions. Yet they do not provide pre-task language activities before the task is introduced, or on other occasions, they alter the TBLT framework by starting with post-task focus-on-form exercises and lists of lexical items and syntactical chunks as well as explicit grammar 
explanations. By avoiding pre-task language activities or replacing them with decontextualized language input and grammar explanations, the teachers turn the preparatory first stage of TBLT into the presentation part of PPP. This has the effect of eliminating the central principle of TBLT and diminishing the overall potential complexity of tasks: with a preceding grammar explanation, the task is no longer a purposeful activity defined by a realworld function that must be negotiated and in turn can provide the meaningful context for subsequent study of the language. Now the task is essentially a communicative exercise in which students manipulate stimuli for the sake of practicing a specific language item: the practice part of PPP. By presenting grammar and phrases to the students instead of eliciting or encouraging recall, discovery, or requests, the teachers minimize the opportunities for students to attend actively to the processes of acquiring language.

These NS ESL teachers also make significant changes to the stages of TBLT that (ought to) follow the task. They do not include the planning and presentation of a report based on the outcomes of the task, both stages where further input and much language-noticing can occur. They reconfigure the post-task focus-on-form activities so that they do not conform to the principles of TBLT. Rather than providing post-task noticing activities that build on short ongoing prompts or responses to students' questions during the task, they interrupt the students' task performance to explain grammar in detail or they wait until after the task to provide explanations and corrections. Once again, these techniques potentially reduce the students' uptake. Often the teachers merge or replace TBLT with guided discovery by starting the task cycle with a task the explicit purpose of which is to set up a grammar discovery exercise, which in turn is followed by a grammar manipulation exercise. This weak version of TBLT is set up such that students know that their teacher will provide them with the answers, thus not motivating the students to inquire after the language and defeating the purpose of discovery learning. Having covered the grammar before, during, and after the task, the teachers avoid task repetition: they believe that the grammatical work of the task and consequently of the students has already been done. When the task cycle is not repeated, the learners' opportunities to develop accuracy, fluen$\mathrm{cy}$, and complexity are minimized.

\section{Conclusion}

Earlier studies of NNS EFL teachers have provided insight into the factors that contribute to their perceptions of, resistance to, and adaptations of TBLT. Yet by focusing predominantly on NNS teachers, these studies have also-perhaps inadvertently_implied that resistance or misunderstanding are specific to NNS EFL teachers. It seems that the EFL/ESL profession assumes that NS teachers understand communicative approaches and can work with them effectively. The profession mythologically conflates native- 
language proficiency with pedagogical knowledge. We show that if this is indeed the impression of research, it is inaccurate and lacks complexity. By reviewing studies of NS teachers of other modern languages and exploring Canadian NS ESL teachers' perceptions and experiences of TBLT, we show that tinkering with tasks knows no bounds: NS ESL teachers are just as likely as NNS EFL or NS modern-language teachers to struggle with and adapt TBLT, and their adaptations are also just as likely to be incongruent with TBLT principles. In a personal communication (June 6, 2008), McDonough remarked that the NS teachers in her study with Chaikitmongkol (2007) also experienced similar difficulties to those of the NNS teachers. We have elaborated on the finding that NS ESL teachers adapt TBLT by indicating specifically how they have adapted it. Just as NNS EFL teachers often turn TBLT into traditional grammar instruction or language practice activities, so NS ESL teachers alter the framework of TBLT, turning it into CLT delivered as PPP.

We contend that scholarship on the implementation of TBLT for EFL/ESL, which has focused on NNS teachers, is misleading if it does not also account for similar issues with NS teachers. It could reiterate stereotyping with respect to the kinds of methods considered appropriate to diverse teachers based on speaker identity. It could inaccurately locate the issue of the difficulty of implementing new, better informed, and more effective teaching approaches in one geocultural sphere and thereby conceal or ignore similar issues in other places while reinforcing a native-speaker/teacher hegemony. By relying on speaker identity as a distinction in undertaking research and a latent and yet cogent factor in its outcomes, attention might unintentionally be directed away from a critical situation in language pedagogy - namely, the faulty implementation of TBLT—that in fact concerns specific aspects of prior teacher education and ongoing professional development needs among all kinds of language teachers, no matter their speaker identity. We suggest downplaying speaker identity as a factor in EFL/ESL teachers' adaptations, and we encourage TESL scholars and teacher educators to find ways to help all teachers better understand the principles and procedures of TBLT. Both NNS and NS teachers require continuing professional development in TBLT, both with regard to developing awareness of their own perceptions and attitudes (Karavas-Doukas, 1996) and in terms of turning a theoretical knowledge base into effective practice that is consistent with theory. The challenge for TBLT is not teachers or even the complexity of the approach, but rather its dissemination.

\section{The Authors}

John L. Plews is an associate professor of German at Saint Mary's University, Halifax, NS. He researches second/foreign-language curriculum and international education for languagelearners and language-teachers, focusing especially on curriculum structure, experience, identity construction, and participant's voice. He has also published on aspects of German culture. 
Kangxian Zhao is a doctoral candidate at the Ontario Institute for Studies in Education/University of Toronto. Her research interests include teacher learning/professional development and the language awareness of second-language teachers and learners. In addition, she has worked on projects on internationally educated teachers and the mental health of immigrants.

\section{References.}

Bruton, A. (2005). Task-based language teaching: For the state secondary FL classroom? Language Learning Journal, 31, 55-68.

Bygate, M., Skehan, P., \& Swain, M. (2001). Introduction. In M. Bygate, P. Skehan, \& M. Swain (Eds.), Researching pedagogic tasks: Second language learning, teaching, and testing (pp. 1-20). Harlow, UK: Pearson Education.

Candlin, C.N. (2001). Afterword: Taking the curriculum to task. In M. Bygate, P. Skehan, \& M. Swain (Eds.), Researching pedagogic tasks: Second language learning, teaching, and testing (pp. 229-243). Harlow, UK: Pearson Education.

Carless, D. (2003). Factors in the implementation of task-based teaching in primary schools. System, 31, 485-500.

Carless, D. (2004). Issues in teachers reinterpretation of a task-based innovation in primary schools. TESOL Quarterly, 38, 639-661.

Carless, D. (2007). The suitability of task-based approaches for secondary schools: Perspectives from Hong Kong. System, 35, 595-608.

Carless, D. (2009). Revisiting the TBLT versus P-P-P debate: Voices from Hong Kong. Asian Journal of English Language Teaching, 19, 49-66.

Carter, K. (1993). The place of story in the study of teaching and teacher education. Educational Researcher, 22(1), 5-12.

Clandinin, D.J., \& Connelly, F.M. (2000). Narrative inquiry: Experience and story in qualitative research. San Francisco, CA: Jossey-Bass.

Conle, C. (2000). Narrative inquiry: Research tool and medium for professional development. European Journal of Teacher Education, 23(1), 49-63.

Connelly, F.M., \& Clandinin, D.J. (1990). Stories of experience and narrative inquiry. Educational Researcher, 19(5), 2-14.

Ellis, R. (2002). The place of grammar instruction in the second/foreign language curriculum. In E. Hinkel \& S. Fotos (Eds.), New perspectives on grammar teaching in second language classrooms (pp. 17-34). Mahwah, NJ: Erlbaum.

Ellis, R. (2003). Task-based language teaching and learning. Oxford, UK: Oxford University Press.

Gatbonton, E., \& Gu, G. (1994). Preparing and implementing a task-based ESL curriculum in an EFL setting: Implications for theory and practice. TESL Canada Journal, 11(2), 9-29.

Gorsuch, G.J. (2000). EFL educational policies and educational cultures: Influences on teachers' approval of communicative activities. TESOL Quarterly, 34, 675-710.

Holliday, A. (1994). Appropriate methodology and social context. Cambridge, UK: Cambridge University Press.

Jeon, I.J., \& Hahn, J.W. (2006). Exploring EFL teachers' perceptions of task-based language teaching: A case study of Korean secondary school classroom practice. Asian EFL Journal, 8(1), Article 8. Retrieved May 3, 2006, from:

http://www.asian-efl-journal.com/March_06_ijj.php

Johnson, K.E. (2006). The sociocultural turn and its challenges for second language teacher education. TESOL Quarterly, 40, 235-257.

Karavas-Doukas, E. (1996). Using attitude scales to investigate teachers' attitudes to the communicative approach. ELT Journal, 50(3), 187-198.

Leaver, B.L., \& Kaplan, M.A. (2004). Task-based instruction in U.S. government Slavic language programs. In B.L. Leaver \& J.R. Willis (Eds.), Task-based instruction in foreign language education. Practices and programs (pp. 47-66). Washington, DC: Georgetown University Press. 
Li, D. (1998). "It's always more difficult than you plan and imagine": Teachers' perceived difficulties in introducing the communicative approach in South Korea. TESOL Quarterly, $32,677-703$.

Littlewood, W. (2004). The task-based approach: Some questions and suggestions. ELT Journal, 58(4), 319-326.

Littlewood, W. (2007). Communicative and task-based language teaching in East Asian classrooms. Language Teaching, 40, 243-249.

Long, M. (1991). Focus on form: A design feature in language teaching methodology. In K. de Bot, R.B. Ginsberg, \& C. Kramsch (Eds.), Foreign language research in cross-cultural perspective (pp. 39-52). Amsterdam: John Benjamins.

Lopes, J. (2004). Introducing TBI for teaching English in Brazil: Learning how to leap the hurdles. In B.L. Leaver \& J.R. Willis (Eds.), Task-based instruction in foreign language education. Practices and programs (pp. 83-95). Washington, DC: Georgetown University Press.

Maly, E. (1993). Task-based instruction: From the teacher's perspective. Dialog on Language Instruction, 9(1), 37-48.

McDonough, K., \& Chaikitmongkol, W. (2007). Teachers' and learners' reactions to a task-based EFL course in Thailand. TESOL Quarterly, 41, 107-132.

Medgyes, P. (1992). Native or non-native: Who's worth more? ELT Journal, 46, 341-349.

Mitchell, R., \& Lee, J. H.-W. (2003). Sameness and difference in classroom learning cultures: Interpretations of communicative pedagogy in the UK and Korea. Language Teaching Research, 7(1), 35-63.

Nunan, D.N. (1991). Communicative tasks and the language curriculum. TESOL Quarterly, 25, 279-295.

Nunan, D.N. (1993). Task-based syllabus design: Selecting, grading, and sequencing tasks. In G. Crookes \& S.M. Gass (Eds.), Tasks in a pedagogical context: Integrating theory and practice (pp. 55-68). Clevedon, UK: Multilingual Matters.

Pavlenko, A., \& Lantolf, J.P. (2000). Second language learning as participation and the (re) construction of selves. In J.P. Lantolf (Ed.), Sociocultural theory and second language learning (pp. 155-177). Oxford, UK: Oxford University Press.

Phillipson, R. (1992). Linguistic imperialism. Oxford, UK: Oxford University Press.

Polkinghorne, D.E. (1995). Narrative configuration in qualitative research. In J.A. Hatch \& R. Wisniewski (Eds.), Life history and narrative (pp. 5-23). London: Falmer Press.

Prabhu, N.S. (1987). Second language pedagogy. Oxford, UK: Oxford University Press.

Richards, J.C., \& Rogers, T.S. (2001). Approaches and methods in language teaching. Cambridge, UK: Cambridge University Press.

Saito-Abbott, Y. (2004). Designing an outcomes-based TBI Japanese language program. In B.L. Leaver \& J.R. Willis (Eds.), Task-based instruction in foreign language education. Practices and programs (pp. 122-141). Washington, DC: Georgetown University Press.

Samuda, V., \& Bygate, M. (2008). Tasks in second language learning. Basingstoke, UK: Palgrave Macmillan.

Skehan, P. (1998). A cognitive approach to language learning. Oxford, UK: Oxford University Press.

Skehan, P. (2003). Task-based instruction. Language Teaching, 36, 1-14.

Smith, D.G. (1991). Hermeneutic inquiry: The hermeneutic imagination and the pedagogic text. In E.C. Short (Ed.), Forms of curriculum inquiry (pp. 187-209). Albany, NY: SUNY Press.

Swan, M. (2005). Legislation by hypothesis: The case of task-based instruction. Applied Linguistics, 26(3), 376-401.

Sun, G., \& Cheng, L. (2002). From context to curriculum: A case study of communicative language teaching in China. TESL Canada Journal, 19(2), 67-86. 
Van Avermaet, P., Colpin, M., Van Gorp, K., Bogaert, N., \& Van den Branden, K. (2006). The role of the teacher in task-based language teaching. In K. Van den Branden (Ed.), Task-based language education. From theory to practice (pp. 175-196). Cambridge, UK: Cambridge University Press.

Van den Branden, K. (2006). Training teachers: Task-based as well? In K. Van den Branden (Ed.), Task-based language education. From theory to practice (pp. 217-248). Cambridge, UK: Cambridge University Press.

Watson Todd, R. (2006). Continuing change after the innovation. System, 34, 1-14.

Willis, J.R. (1996). A framework for task-based learning. Harlow, UK: Longman.

Xu, J., Liu, F., \& Jiang, M. (2008). Task-based language teaching: From the practical perspective. In International conference on Computer Science and Software Engineering 2008 (pp. 1054-1057). Piscataway, NJ: IEEE.

$\mathrm{Yu}, \mathrm{L}$. (2001) Communicative language teaching in China: Progress and resistance. TESOL Quarterly, 35, 194-198. 